\title{
PARTIDO POLÍTICO - FUNCIONAMENTO PARLAMENTAR - BLOCO PARLAMENTAR
}

\section{CONSULTA}

O Excelentíssimo Senhor Deputado Michel Temer, Presidente da Câmara dos Deputados, honra-me com a consulta transcrita a seguir.

Senhor Ministro,

Cumprimentando-o, tenho a honra de solicitar a Vossa Excelência, a elaboração de $\mathrm{Pa}$ recer Jurídico sobre o funcionamento parlamentar dos Partidos Políticos.

Como é sabido, a Constituição de 1988, inovando, nesse particular, em relaçāo às anteriores, erigiu o "funcionamento parlamentar de acordo com a lei", entre os preceitos que deveriam ser observados pelos Partidos Políticos (art. 17, IV, da Constituição Federal).

Nossa Carta Política, em seus artigos 51, inciso III e 52, inciso XII, dá à Câmara dos Deputados e ao Senado Federal, respectivamente, a competência privativa de elaborar seus regimentos intemos.

O Regimento Interno da Câmara dos Deputados, aprovado pela Resolução $\mathrm{n}^{\underline{1}} 17$, de 1989, dispõe sobre o agrupamento de Deputados por representações partidárias (Bancadas) ou de Blocos Parlamentares, estabelecendo que, quando a respectiva representação for igual ou superior a um centésimo da composição da Câmara, cabe-lhes escoIher um Lider (artigo 9", caput e $\$ 4$ ).

À ediçāo do Regimento Interno desta Casa, sobreveio a Lei n 9.096, de 19 de setembro de 1995 (Lei dos Partidos Políticos), que, em eu capítulo $I I$, disciplina o funcionamento parlamentar, estabelecido, no artigo 12 , in verbis:
"Art. 12 - O partido político funciona, nas Casas Legislativas, por intermédio de uma bancada, que deve constituir suas lideranças de acordo com o estatuto dos partidos, as disposiçōes regimentais das respectivas Casas e as normas desta Lei."

$O$ artigo 13 da mesma Lei, fixa requisitos para o funcionamento parlamentar baseado nos votos obtidos pelo Partido em cada eleição para a Câmara dos Deputados. Os artigos 56 e 57 contêm regras transitórias aplicáveis à Legislatura que está a expirar e ao periodo que vai de $1^{a}$ de fevereiro vindouro até a proclamação dos resultados da eleição de 2006.

Em face do exposto, e pendo em vista as disposiçōes constitucionais sobre a questão, o Regimento Interno desta Casa e a Lei $n^{\varrho}$ 9096/95, consulto Vossa Excelência sobre os seguintes pontos:

I - O que se entende por " funcionamento parlamentar"?

a) Seria o direito de uma agremiação partidária funcionar como Partido nas Casas Legislativas, por meio de uma Bancada?

b) Não atendendo o Partido às exigências legais para seu funcionamento parlamentar, deverão os mandatários eleitos sob sua legenda atuar, no âmbito da Câmara dos Deputados, como se fossem representantes isolados, não podendo se beneficiar de prerrogativas decorrentes de proporcionalidade partidária?

II - Pode a Lei formal, emanada do Poder Legislativo e com a sançāo do Executivo, dispor sobre funcionamento parlamentar, ou se trata de matéria reservada à disciplina priva- 
tiva de cada Casa Legislativa, por meio de seus regimentos internos?

III - Em caso afirmativo, havendo conflito entre a lei (no caso, a Lei dos Partidos Políticos) e o Regimento Interno, qual disciplina deve prevalecer?

IV - E quanto aos Blocos Parlamentares, poderão eles ser constituídos mediante a reuniāo de partidos que nāo preencham os requisitos para o funcionamento parlamentar, ainda que, ao menos um deles preencha tais requisitos?

$\mathrm{V}$ - Quanto à inteligência do caput do artigo $9^{\circ}$ e do seu $\$ 4^{\circ}$ do Regimento Interno da Câmara dos Deputados, frente ao que dispōe o artigo 12 da Lei no 9.096, de 1995:

- poderá um Partido, com representação superior a um centésimo da composição da Casa, escolher um Líder para atuar no âmbito da Câmara dos Deputados, se este mesmo Partido não preencher qualquer dos requisitos de funcionamento estabelecidos pelos artigos 13 ou 57 da referida Lei $n^{0}$ 9.096/95?

Atenciosamente,

Michel Temer

Presidente da Câmara dos Deputados

\section{PARECER \\ FUNCIONAMENTO PARLAMENTAR DOS PARTIDOS POLÍTICOS}

1. Sāo os partidos políticos pessoas jurídicas de direito privado (Const. art. $17, \S 2^{2}$ ). ${ }^{1}$ Gozam, por isso, do satus libertatis, por força do qual somente a lei os pode obrigar a fazer ou deixar de fazer alguma coisa (Const. art. 5 , inc. II). No ordenamento jurídico fundado nas Constituições precedentes, o estatuto que Ihes autorizava a criação, regulava o funcionamento e determinava a extinção, atribuíalhes personalidade jurídica de direito público interno (Lei no 1.164. de 24.07.1950, art. 132; Lei $\mathrm{n}^{\mathrm{o}}$ 4.740. de 15.07.1965, art. 20; Lei $\mathrm{n}^{\mathrm{O}}$ 5.682 , de 21.07 .1971 , art. $2^{\circ}$, com a redação que lhe deu o art. 12, da Lei $n^{2} 6.767$, de 20.12.1979). Eram, por isso, os partidos da mesma natureza do Estado, cujos órgãos só podem fazer o que a lei consente (Princípio da vinculação à lei, Const. art. 37, caput). Sob a Constituição vigente. porém, o princípio de legalidade da ordem pública já nāo lhes constitui mais a regra do agir, mas, sim, o princípio de legalidade da ordem privada, em razão do qual a conduta dos seus sujeitos, sendo livre em regra, só por ato formalmente legislativo pode ser imposta, permitida, proibida ou reprimida (L.7, D. De Legibus).

2. Porque os partidos políticos eram, então, entes públicos, as Constituições de 1946 e 1967 e as leis orgânicas especiais lhes atribuíam, desde logo, uma necessária participação na eleição de representantes à Câmara dos Deputados (Consts. 1946, art. 134; 1967, art. 143; E.C. n² $1 / 69$, art. 148), na organização das Casas do Congresso (Const. 1946, art. 40, parágrafo único, alínea a) e na ordenação da vida parlamentar (Consts. 1946, art. 48, § 1; 1967 , art. $48, \S 22$, E.C. $n^{2} 1 / 69$, art. $48, \S 32$ ).

3. Como consequiência natural do regime de autonomia e plena capacidade civil dos partidos, que adota, a Constituição vigente deu à lei o poder de definir-lhe o direito de concorrerem para o funcionamento das instituiçōes parlamentares. Isto só por lei se poderia fazer porque, sendo os partidos entes de direito privado, só obedecem às disposições legislativas; e também porque. se a norma legal é ameaçada ou lesada, podem os seus sujeitos obter proteção judicial, garantia dada pela Constituição a todos os titulares de direitos subjetivos (Const. art. 50, XXXV).

Contudo, a lei que dispōe sobre o funcionamento parlamentar dos partidos está mate-

1 V. JOSÉ AFONSO DA SILVA, Curso de Direito Constitucional Positivo, 5 a edição, Edit. RT, 1989. pgs. 346-347: "Liquida-se, com isso, qualquer pretonsão de enquadrá-los como órgäos do Estado, pois, órgão, no sentido técnico, segundo a doutrina mais corrente, näo tem personalidade jurídica, e menos ainda personalidade juridica de direito privado - serão eles instituições no sentido concebido por Maurice Hauriou: "idéia objetiva transformada em uma obra social por um fundador, idéia que recruta adesōes no meio social e sujeita assim a seus serviços vontades subjetivas indefinidamente renovadas." 
rialmente vinculada e limitada aos fins e temas preestabelecidos na Constituição. Entre os fins nela expressos,

a) a autenticidade do regime representativo:

b) a correspondência da conduta dos representantes ao mandato político que receberam (Const. art. 17, § 19);

c) a ponderação equitativa das opiniões sufragadas pelo eleitorado, nos procedimentos, resoluçōes e decretos do Congresso Nacional (Const. art. 58, \& 1²);

d) a formação política da opinião pública. mediante o acesso gratuito ao rádio e à televisāo (Const. art. 17, § 3).

mas, mesmo nos estatutos dos partidos, editados sob a autoridade das ordens constitucionais precedentes, respeitava-se a antiga tradição de inviolabilidade da autonomia - que é sempre normativa - e da independência de natureza operativa - dos parlamentos. Ambas estavam asseguradas na norma iterativamente repetida das nossas cartas republicanas, segundo a qual, como se diz uniformemente nos artigos 51, IV e 52, XIII, da Constituiçāo vigente, compete à Câmara dos Deputados e ao Senado Federal.

"dispor sobre sua organizaçāo, funcionamento, polícia, criaçāo, transformação ou extinção de cargos, empregos e funçōes dos seus serviços, e a iniciativa de lei para fixação da respectiva remuneração, observados os parâmetros estabelecidos na lei de diretrizes orçamentárias."

Sempre se entendeu que não existe relação de subordinaçāo da norma regimental à lei formal e que essas atribuiçōes são exclusivas, não admitem partilha, nem concorrência. Com base em disposições constitucionais idênticas, semelhantes ou análogas deduziuse a proposição jurídica segundo a qual, nos parlamentos, a situação e os atos das representaçōes partidárias, de efeitos exclusivamente internos, mesmo aqueles para os quais os partidos estão legitimados pela Constituição, são regulados por normas regimentais. Mas, nos atos e relaçōes jurídicas que produzem efeitos extra muros, ou seja, nas pessoas e nas coisas não sujeitos à autoridade das
Mesas e dos plenários, os partidos, como quaisquer outros particulares, regulam-se por lei formal.

4. Sem embargo dessa legitimação constitucional para a participaçāo nos atos de natureza pública e conteúdo político acima indicados, os partidos não são titulares do mandato que, no regime representativo, habilita ao exercício do poder legislativo. A Constituição nomeia os únicos titulares da representação política no artigo 45 (" $A$ Câmara dos Deputados compõe-se de representantes do povo, eleitos, pelo sistema proporcional, em cada Estado e no Distrito Federal") e no artigo 46 ("O Senado Federal compõem-se de representantes dos Estados e do Distrito Federal, eleitos segundo o principio majori. tário"). Sāo, portanto, pessoas naturais, deputados e senadores, os titulares únicos dos mandatos políticos eletivos que os autorizam a legislar, colegiadamente, sobre as matérias de competência da União (Const. art. 48, ca$p u t)$ e a exercer todas as atribuições do Congresso Nacional como seus órgãos. Por sua vez, os senadores e os deputados, protegidos, no exercício do mandato, pela inviolabilidade de suas opiniões, palavra e votos, têm com seus partidos uma relação de mera filiação regulada pelos estatutos que, consensualmente, adotam; filiação que lhes é exigida pela Constituição, como requisito de elegibilidade (art. 14, $\S 3^{\circ}, \mathrm{V}$ ). Os senadores e os deputados são associados das agremiaçōes políticas sob cuja legenda se elegeram e a eles aplicam-se as disposiçōes constitucionais atinentes ao direito subjetivo de associação. E, nos termos do artigo $5^{\circ}$. inciso $\mathrm{XX}$, da Constituição, o senador ou deputado que se filia a um partido não pode ser compelido a permanecer a ele associado ou filiado.

5. Some-se a essa disposiçāo de direito constitucional positivo o postulado fundamental do mandato político moderno - a não subordinaçāo do mandatário aos eleitores que lhe acrescenta a qualidade de ser livre, na conformidade da dupla qualificaçāo que a doutrina consagrou: mandato político ou livre. Definiu-o BURKE com insuperável eloquêencia e honesta exatidāo, no discurso aos seus eleitores de Bristol: 
"Certainly, gentlemen, it ought to be the happiness and glory of a representative to live in the strictest union, the closest correspondence, and the most unreserved communication with his constituents. Their wishes ought to have great weight with him; their opinion, high respect: their business, unremitted attention. It is his duty to sacrifice his repose, his pleasures, his satisfactions, to theirs: and above all, ever, and in all cases, to prefer their interest to his own.

But his unbiassed opinion, his mature judgement, his enlightened conscience, he ought not to sacrifice to you, to any man, or to any set of men living. These he does not derive from your pleasure; no, nor from the law and the constitution. They are a trust from Providence, for the abuse of which he is deply answerable. Your representative owes you, not his industry only, but his judgement; and he betrays instead of serving you, if he sacrifices it to your opinion." 1

Foi, certamente em respeito à natureza livre do mandato político, admiravelmente explicada por BURKE, que o constituinte incluiu as normas de fidelidade partidária na autonomia dos partidos políticos para dispor sobre sua organização e funcionamento (Const. art. $17, \S 1^{\circ}$ ). Segue-se, daí, que não cabe nem à lei, nem ao regimento comum do Congresso ou aos regimentos internos das suas Casas, impor aos parlamentares fidelidade aos partidos, nem, no silêncio da Constituição, dar efeitos de direito público a fatos que só são juridicamente relevantes na esfera das associaçōes privadas (Lei $\mathrm{n}^{2} 9096$, de 19 de setembro de 1995, art. 25).

Para os membros do Congresso Nacional a consequiência juridicamente necessária do abandono da legenda pela qual se elegeram é a perda das posições que ocupam, como representantes do partido ou em virtude do prin- cípio da proporcionalidade partidária, nos órgãos da Câmara dos Deputados e do Senado Federal (Const. art. 58, § 10; Lei n 9096, de 1995, art. 26).

6. Essas proposições jurídicas explicam o sentido e determinam o alcance da disposição do artigo 12, da lei dos partidos políticos, que legitima as bancadas, não os partidos políticos, para funcionar no âmbito dos corpos legislativos do país.

$\mathrm{Da}$ independência do órgão colegiado do Poder Legislativo e da inviolabilidade dos seus membros, no exercício do mandato, resulta a impossibilidade de lhes regular a conduta parlamentar por lei formal, dado que, assim, facultar-se-ia a intromissão da outra Casa e do Presidente da República em assunto entregue à autonomia de cada uma das Câmaras.

Essa impossibilidade se estende, com muito maior razão, à inserção de uma pessoa jurídica de direito privado no funcionamento do Congresso Nacional. No começo da era republicana, pretendeu-se justificar a delegação de atribuiçōes do Congresso ao Presidente da República, como forma de agilização do funcionamento parlamentar, porque, dizia-se, a função se distingue do poder de legislar e o Presidente da República, quando baixa decretos com força de lei, é mero instrumento do Parlamento. PAULO M. DE LACERDA ${ }^{2}$, apontando a violência que as delegaçōes legislativas faziam à independência do Congresso, lembrava que a função "consiste no exercício do ato" e que um órgão político ele próprio é o instrumento funcional (...) “criado pela constituição exatamente nesse caráter de instrumento orgânico para o exercicio do poder, para a função." Igualmente, o funcionamento, parlamentar dos partidos não pode conferir-lhes, como pessoas jurídicas, o exercício de qualquer atividade própria do Congresso Nacional e de suas Casas, mormente quando a própria Constituição inclui entre os

I EDMUND BURKE, Speeches and Letters on American Affairs, London, J.M. Dent \& Sons Ltd.. 1950, pgs. 72-73.

2 PAULO M. DE LACERDA, Direito Constirucional Brasileiro, Liv. Azevedo Editora, vol. II, pgs. 136-137. 
atributos da autonomia da Câmara dos Deputados e do Senado Federal o de dispor sobre o seu funcionamento.

Precisamente para não incorrer em igual violência contra a independência e autonomia do Congresso Nacional, a Lei $n^{2} 9.096$, de 1995, dá às bancadas, isto é, ao agrupamento dos titulares de mandatos eletivos, o exercício da representação política nas Casas do Congresso Nacional.

7. As bancadas são instituições de direito parlamentar exclusivamente. Constituem-se, nos corpos legislativos, pela reunião dos representantes que se identificam pela unidade de propósito e pela uniformidade da atuação. Agrupam-se sob a liderança que designam.

As bancadas, como os blocos parlamentares, não têm personalidade jurídica privada ou pública. $O$ líder é órgão de expressão do seu pensamento e de coordenação de suas ações. Onde não há líder não há bancada, se há líder, há bancada (ubi episcopus, ibi ecclesia). Compōem uma bancada, na Câmara, os Deputados que se elegeram pela mesma legenda partidária (Regimento Interno, artigo 90: "Os Deputados são agrupados por representações partidárias..."); a lei dos partidos políticos acrescenta que é por meio de suas bancadas que os partidos funcionam nas Casas Legislativas (Lei $\mathrm{n}^{2}$ 9.096, de 1995, art. 12: " $O$ partido político funciona, nas Casas Legislativas, por intermédio de uma bancada, que deve constituir suas lideranças de acordo com o estatuto do partido, as disposifões regimentais das respectivas Casas e as normas desta Lei.").

Os estatutos e normas partidários têm como sujeitos e destinatários os deputados e senadores, na condição de filiados ou associados do partido; mas não se sobrepõem, nem se incorporam ao ordenamento interno e autônomo das Câmaras.

Da mesma maneira e como instituição exclusivamente parlamentar a bancada é integralmente regulada por norma regimental.

As normas dos partidos, porque vinculam os associados, podem ser aplicadas à escolha dos líderes, como quer a Lei n 9.096, de 1995 (art. 12); não, contudo, à definição das condutas que lhes sāo permitidas ou proibidas nas
Casas em que atuam, nem dos direitos e prerrogativas de que, nelas, desfrutam.

A Lei n 9.096, de 1995, atenta a essas disposiçōes e à autonomia das Casas do Congresso Nacional, separa a atuação dos partidos dentro e fora dos corpos legislativos. Fora age a pessoa jurídica de direito privado, capaz para os atos da vida civil e titular de prerrogativas eleitorais; dentro, são os dentetores de mandatos políticos que perseguem concertadamente os fins programáticos em torno dos quais se reúnem, constituindo as diferentes bancadas. E somente essas participam da vida e da atividade parlamentar. Essa é a única interpretação compatível com o princípio da autonomia do Congresso Nacional, da inviolabilidade de seus membros e de seus plenários (Const. art. 51, IV; 52, XIII; 53) e com as normas constitucionais atinentes ao direito individual de associação e ao status das agremiaçōes de quaisquer finalidades (Const. art. 52, incisos XVII a XXI).

8. A Constituição de 1988 parece-me não ter rompido, no que diz respeito à autonomia das Casas do Congresso, com a orientação das cartas políticas que a precederam, pois, como vimos, os artigos 51, incisos III e IV, e 52, incisos XII e XIII, consagram-na.

Cabe, pois, perguntar como se há de entender a delegaçāo do artigo 17, inciso $\mathrm{IV}$, da Constituição, ao legislador ordinário para dispor sobre o funcionamento parlamentar dos partidos.

Essas normas legais têm um limite material de validade que são precisamente os atos, fatos e relaçōes sujeitas às regras e ao império ou poder de polícia do Congresso e de suas Casas. Caem sob a autoridade da lei os fatos, atos e relaçōes que não se podem regular por norma interna do parlamento. $\mathrm{E}$, como assinalou-se acima (item 7), a Lei no 9.096, de 1995, não legitima o partido político para agir no âmbito do Congresso, mas transfere a uma instituição de direito parlamentar, a bancada, o encargo de dar-lhe curso ao programa e resoluções. Exaure-se aí o conteúdo preceptivo da lei no ponto atinente ao funcionamento parlamentar dos partidos políticos. Essa disposição produz, ainda, o efeito de sujeitar os 
fatos. atos e resoluções das bancadas. como expressões parlamentares dos partidos, às resoluçōes da Câmara e do Senado.

9. Contudo, a norma restritiva do artigo 13 , da Lei $n^{2} 9.096$, de 1995, dispõe diretamente sobre fatos, atos e resoluçōes que nascem e se esgotam no âmbito do Congresso Nacional. Com efeito a reunião de representantes eleitos sob a mesma legenda em uma bancada tem por escopo o gozo de prerrogativas e a prática de atos que só são juridicamente relevantes na vida congressual e, por isso, são regulados pelo regimento das Casas ou do Congresso, jamais pela lei que pressupõe a sanção e o veto, bem como a iniciativa, do Chefe do Poder Executivo, o que constituir-se-ia em intervenção em assunto da economia interna do parlamento.

Mas não é, apenas, pela violação da autonomia do Congresso Nacional que o artigo 13, da Lei n 9.096, de 1995, não me parece compatível com a Constituição. Também nāo o é porque dá a um fato eleitoral', uma conseqüência que ele, juridicamente, não pode produzir.

O voto emitido, em sistema proporcional, na eleição para a Câmara dos Deputados, tem, constitucionalmente, a finalidade única de outorgar mandato político representativo (Const. art. 45). Conferido este pela Justiça Eleitoral em decisão coberta pela preclusāo ou eventualmente protegida pela coisa julgada. ${ }^{2}$ não pode o legislador dar aos votos recebidos pelo partido e pelos deputados eleitos por sua legenda efeito restritivo do direito declarado judicialmente; ainda mais quando tal restriçāo não é admitida pela Constituiçāo e não foi aplicada pelo ato judicial.

\section{CONCLUSĀO}

Respondendo, enfim, as questões suscitadas na consulta, tenho que, na conformidade da disposição do artigo 12 , da Lei $n^{2} 9.096$. de 1995, não é o partido, pessoa jurídica de direito privado, que funciona nas Casas Legislativas, mas a bancada constituída pelo agrupamento dos representantes que se elegeram sob a legenda partidária. Parece-me, ainda. que essa norma harmoniza os conteúdos dos artigos 17. IV: 51 , IV e 52, XIII, da Constituição, permitindo que o mandato político seja exercido de acordo com as diretrizes dos partidos, mas sem ofensa à independência e autonomia do Congresso Nacional (I.A). As condiçōes para o agrupamento de uma representação partidária em bancada são ditadas por resolução de cada uma das Casas do Congresso. Cabe às suas leis internas fixar os critérios de determinação da proporcionalidade partidária a ser observada na composição dos órgãos da Câmara dos Deputados e do Senado Federal. (I.B)

A lei formal tem limites materiais de validade. Não pode dispor, por exemplo, sobre o que é lícito ou ilícito pensar. Nada pode autorizar que viole a casa de mordia, fora das hipóteses constitucionalmente admitidas (Const. art. 5, XI). Nāo pode proibir que se creia ou preste culto a Deus (Const. art. 5\%. VI). Não pode regular os deveres, direitos, prerrogativas, atos e situações internas dos membros do parlamento; não pode dizer como as leis são elaboradas, nem como se contarão os votos dos membros da Câmara e do Senado nas deliberaçōes sobre proposiçōes que nelas tramitam; nem como se organizarāo os grupos e frações parlamentares e a quais deles permite-se escolher líder.

1 Cf. GIOVANNI SCHEPIS. I Sistemi Eletrorali. Edit Caparrini - Empoli, pg. 113, da seçāo Segunda: "a lei eleitoral de 15 de junho de 1949, da República Fedesal de Alemanha excluiu da atribuiçäo de mandatos no Land as listas dos partidos que näo conseguissem una cifra eleitoral igual, pelo menos, a 5\% dos votos válidos no Land ou que não houvessem conquistado um colégio uninominal". V. ainda ALFRED GROSSER. La Démocratie de Bonn. Edit. Armand Colin. 1958. pg. 95.

2 JEANCLAUDE MASCLET, Droit Électoral, Presses Universitaires de France, 1989. pg. 370: “La décision rendue en matière électorale est revêtue de l'autorité de la chose jugée. Elle n'a pas en principe de caractér e immédiatement exécutoire. "(...) "La décision rendue a un effet erga omnes". 
Pode a lei dispor, ex.gr., sobre o uso. a cessão. o comodato de bens públicos aos partidos, inclusive os bens da Uniāo sob administração das Casas do Congresso Nacional: sobre as relações jurídicas de conteúdo patrimonial ou obrigacional entre eles. Nada pode com relação aos fatos, atos e relações que começam e terminam no Congresso Nacional e só nele produzem efeitos.(II)

No conflito da lei com o Regimento Interno prevalece a norma emanada da autoridade competente, segundo a Constituição. (III)

$\mathrm{O}$ que até aqui se disse prejudica a resposta ao quesito IV da consulta. Contudo, deve-se esclarecer que o agrupamento das representações partidárias em blocos parlamentares regula-se inteiramente pelo Regimento Interno.

Respondo afirmativamente ao quesito $\mathrm{V}$. O requisito a ser preenchido pelas representaçōes partidárias para que indiquem líder é o do artigo 92, parágrafo 40, do Regimento Interno da Câmara dos Deputados. É o meu parecer.

Rio de Janeiro, 27 de janeiro de 1999. Célio Borja 